\title{
Transaortic valve replacement, complications and validation of a protocol in ICU
}

\author{
A Berrazueta*', C Carbajales, JM Ayuela-Azcarate, E Martinez Barrio, P Tejedor, E Portugal, M Valle, M Gero \\ From ESICM LIVES 2015 \\ Berlin, Germany. 3-7 October 2015
}

\section{Introduction}

Aortic stenosis(AS) is the most prevalent valvular disease (incidence $2 \%$ over 65years). Valvular area decreases $0.3 \mathrm{~m} / \mathrm{s} / \mathrm{y}$, transvalvular gradient $(7 \mathrm{mmHg} / \mathrm{y})$ and blood $\operatorname{speed}(0.3 \mathrm{~m} / \mathrm{s} / \mathrm{y})$ increases with age. AS treatment can be medical or surgical:heart valve replacement surgery or percutaneous placement of an aortic endoprothesis (TAVR) in patients with high perioperative risk. TAVR is beneficial and improves their expectative and quality of life (QOL) compared with medical treatment.

\section{Objectives}

To describe the incidence of complications of TAVR and to determine the validity of our protocol.

\section{Methods}

Descriptive observational study during 2012-2014 of TAVR complications with Corevalve device at Burgos University Hospital. We analyzed epidemiological characteristics, comorbidities, and complications. We applied the actual protocol in all patients, which consist in femoral artery access, provisional pacemaker(PM), antibiotic and high digestive bleeding prophylaxis. During TAVR patients are superficially sedated and ventilated with self-expanded balloon. Afterwards patients are admitted to ICU continuing hemodynamic monitoring, neurologic vigilance, and vascular access care hourly. Systematically and detailed echocardiography is made. Double antiaggregation and haemoglobin are optimized. Seriated blood tests are taken. If there is no atrioventricular block(AVB) after 24 hours the PM is removed.

\section{Results}

We analyze 22 patients with severe AS undergoing TAVR, with good QOL and comorbidities similar to those described in table 1. Mean age 84.2years (SD 5.063), 68.2\% women. Median APACHE II score 13 and mean Euroscore 17.

Complications in ICU (Table 2): blood transfusion $63.7 \%$, acute kidney injury(AKI) $31.8 \%$, AVB $27.3 \%$ (definitive PM); stroke(9.1\%), and absence of infection. Three patients had a cardiac arrest during the procedure (TAVR was not implanted) and only one of them survived. TAVR migration occurred once and required recolocation.

\section{Conclusions}

TAVR using our protocol is a safe technique but not free of complications in patients with high surgical risk. Most of these complications were transfusion requirements, conduction system abnormalities, and AKI resolved at discharge. No nosocomial infections or need of prolonged mechanical ventilation was observed. These results are comparable to the experience in other centers, so we validate our protocol.

\section{Table 1. Patient's Comorbidities}

\begin{tabular}{ll}
\hline Arterial Hypertension(AHT) & $77 \%$ \\
\hline Cardiac Insufficiency & $54.5 \%$ \\
\hline Atrial Fibrillation & $45.5 \%$ \\
\hline Coronary disease & $45.5 \%$ \\
\hline Acute Kidney Injury(AKI) & $34.4 \%$ \\
\hline Diabetes Mellitus & $22.7 \%$ \\
\hline Pulmonar Hypertension & $22.7 \%$ \\
\hline Obesity & $9.1 \%$ \\
\hline Artheriosclerosis & $9.1 \%$ \\
\hline Ictus & $9.1 \%$ \\
\hline
\end{tabular}

Burgos University Hospital, Intensive Care, Burgos, Spain 
Table 2. Complications after TAVR implantation

\begin{tabular}{ll}
\hline Residual Aortic Regurgitation & $18.2 \%$ \\
\hline Cardiac Arrest & $18.2 \%$ \\
\hline Valvular migration and prosthesis recolocation & $4.2 \%$ \\
\hline Malignant arrhythmias & $4.2 \%$ \\
\hline Pneumothorax & $4.2 \%$ \\
\hline Mechanical Ventilation & $9.1 \%$ \\
\hline ICU Stay & 2.7 (SD 0.3) \\
\hline Hospital Stay & 11.23 (SD 1.36) \\
\hline 30 days Mortality & $13.6 \%$ \\
\hline 1 year Mortality & $13.6 \%$ \\
\hline
\end{tabular}

Published: 1 October 2015

\section{References}

1. Data I, Burzotta F, Trani C, Crea F, Ussia GP: Percutaneous management of vascular access in transfemoral transcatheter aortic valve implantation. World J Cardiol 2014, 6(8):836-846.

2. Toggeweiler S, Leipsic J, Binder RK, Freeman M, Barbanti M, Heijmen RH, et al: Management of Vascular Access in Transcatheter Aortic Valve Replacement. Part 2:Vascular Complications. JACC Cardiovasc Interv 2013, 6(8):767-776.

3. Stahli BE, Maier W, Corti R, Luscher TF, Jenni R, Tanner FC: Aortic regurgitation after transcatheter aortic valve implantation: mechanisms and implications. Cardiovasc Diagn Ther 2013, 3(1):15-22.

4. Piazza N, Lange R, Martucci G, Serruys PW: Patient selection for transcatheter aortic valve implantation: Patient risk profile and anatomical selection criteria. Arch Cardiovasc Dis 2012, 105(3):165-173.

doi:10.1186/2197-425X-3-S1-A542

Cite this article as: Berrazueta et al:: Transaortic valve replacement, complications and validation of a protocol in ICU. Intensive Care Medicine Experimental 2015 3(Suppl 1):A542.

\section{Submit your manuscript to a SpringerOpen ${ }^{\mathcal{O}}$ journal and benefit from:}

- Convenient online submission

- Rigorous peer review

- Immediate publication on acceptance

- Open access: articles freely available online

- High visibility within the field

- Retaining the copyright to your article 